\title{
Teatro de fantoche como estratégia de ensino: relato da vivência
}

\author{
Puppet theatre as teaching strategy: a report of the experience
}

Teatro de títeres como estrategia de enseñanza: un relato de la vivencia

\section{Débora Alves de Lima Rampaso', Maria Aparecida Gonçalves Doria', Maria Cláudia Martins de Oliveira', Gilberto Tadeu Reis da Silva"}

\author{
' Faculdade Santa Marcelina, Curso de Graduação em Enfermagem. (Enfermeiras graduadas) São Paulo-SP, Brasil. \\ " Faculdade Santa Marcelina, Curso de Graduação em Enfermagem, Núcleo de Ensino, \\ Pesquisa e Extensão de Formação e Educação em Saúde. (Líder) São Paulo-SP, Brasil.
}

Submissão: 19/02/2010 Aprovação: 27/07/2010

\section{RESUMO}

No quinto semestre do curso de graduação em enfermagem é desenvolvida a disciplina de Didática Aplicada ao Cuidado. Esta disciplina desenvolve vários conteúdos teórico-práticos, dentre eles o de estratégias de ensino. Diante deste tema e do projeto político pedagógico do curso, propusemos uma articulação interdisciplinar, e optamos por relatar nossa vivência com o teatro de fantoches na promoção à saúde bucal de crianças de uma creche na Zona Leste de São Paulo. Com esse relato, evidenciamos que os conteúdos teóricos desenvolvidos na Disciplina de Didática Aplicada ao Cuidado são fundamentais para a prática da Educação em Saúde.

Descritores: Enfermagem; Educação em Enfermagem; Educação em Saúde; Materiais de ensino.

\section{ABSTRACT}

The Didactics Applied to Care discipline is developed in the fifth semester of the nursing graduation course. It develops several theoretical-practical contents, among them, the teaching strategy. Our objective is to report the experience with the use of puppet theater to promote the oral health of children in a day nursery in the São Paulo East Zone. With this report we make it clear that the theoretical contents developed by the Didactics Applied to Care Discipline are essential to the practice of Health Education. The discipline allows us to develop multiple activities in the role of educator and in health promotion.

Key words: Nursing; Nursing Education; Health Education; Teaching materials.

\section{RESUMEN}

En el quinto semestre del curso de graduación en enfermería es desarrollada la disciplina de Didáctica Aplicada al Cuidado. Esta desarrolla varios contenidos teórico-prácticos entre ellos el de estrategia de enseñanza. El objetivo es relatar la vivencia de la utilización del teatro de títeres en la promoción de la salud bucal de niños de una guardería en la Zona Este de San Pablo. Con este relato evidenciamos que los contenidos teóricos desarrollados en la Disciplina de Didáctica Aplicada al Cuidado son fundamentales para la práctica de la Educación en Salud. La disciplina nos permite desarrollar múltiples actividades en el papel de educador y en la promoción de la salud.

Palabras clave: Enfermería; Educación en Enfermería; Educación en Salud; Materiales de Enseñanza. 


\section{INTRODUÇÃO}

Muitos educadores, mesmo aqueles que trabalham com adultos afirmam que as brincadeiras, os jogos e os teatros são importantes para a educação. Dohme ${ }^{(1)}$, afirma que o uso do lúdico é a melhor forma de transmissão de conhecimentos; auxilia no interesse, motivação, engajamento, avaliação e fixação do conteúdo apresentado. O aprendizado ocorre dentro do "mundo" da criança, das coisas que lhes são naturais e importantes de fazer, que respeitam as características próprias da idade seus interesses e esquemas de raciocínio próprio.

Por lúdico entende-se o que se refere aos jogos, ao divertimento e à recreação ${ }^{(2)}$. Na prática, alguns educadores acreditam que o lugar de brincadeiras é depois da parte teórica; outros mesclam o lúdico dentro do processo ensino-aprendizagem. Todavia, independente do momento, o lúdico suscita conhecimentos teóricos e aprofundamentos práticos bem como uma ação que a criança faz de forma autônoma e espontânea sem o domínio de um adulto.

Segundo o filósofo Johan Huizinga, existem quatro elementos em uma ação lúdica: a) é livre; b) têm objetivos e regras próprias; c) tem uma limitação de tempo e de espaço e é jogado até o fim dentro desses limites; d) é uma evasão temporária da vida real para uma atividade temporária ${ }^{(1)}$.

No quinto semestre do Curso de Graduação em Enfermagem é desenvolvida a disciplina de Didática Aplicada ao Cuidado. Esta disciplina desenvolve vários conteúdos teórico-práticos dentre eles o de estratégias de ensino. Diante deste tema e do projeto político pedagógico do curso propusemos uma articulação interdisciplinar, e objetivamos com este artigo descrever a vivência de uma estratégia de ensino focada na promoção à saúde de crianças de uma creche, por meio a utilização do teatro de fantoches.

\section{METODOLOGIA}

No Curso de Graduação em Enfermagem desenvolvemos várias inserções em cenários de prática a partir do primeiro semestre. Nas abordagens da temática em saúde da criança, empreendemos ações voltadas à Pediatria Social, sendo um dos locais desta vivência uma creche. Neste período, foi solicitada atividade educativa com as crianças, na faixa etária de 3 a 4 anos de idade. Mediante a necessidade da orientação na área de saúde bucal, optamos pela utilização de teatro de fantoches.

O teatro pode ser visto como um jogo dramático completo, pois consegue alcançar a criança em toda a sua globalidade, abrangendo a criatividade e o aprendizado por meio da descontração. É embasado nas representações de momentos, situações ou problemas, envolvendo uma prática coletiva e social, muito presente em nossos tempos atuais, despertando a criatividade e o faz-de-conta; nesse sentido a criança tem direito de observar e aprender sobre o que ocorre em seu cotidiano ${ }^{(3)}$.

Para o planejamento, desenvolvimento e elaboração desta ação educativa o grupo organizou-se, cada qual com responsabilidades definidas: produção e elaboração da história, organização e execução do plano proposto, integração com as crianças e elaboração e aplicação de um exercício de fixação para a prática apresentada. Na produção textual abordamos os seguintes aspectos: cáries e suas causas, técnica da escovação e uso do fio dental, visita ao dentista e alimentação saudável.

Entendendo a importância do preparo prévio e implementação do planejamento proposto, promovemos a realização de ensaio do teatro a fim de aperfeiçoar a interação entre os fantoches, gerar segurança no momento da apresentação e mensurar o tempo despendido para realização desta tarefa.

A organização das crianças se deu no refeitório, onde estava montado o cenário para apresentação. Percebemos a curiosidade, expectativa e ansiedade das crianças antes da apresentação, já durante a apresentação o sentimento foi de fascinação, alegria e motivação para o novo aprendizado. Interagindo ludicamente com o mundo real, a criança estabelece uma harmonia e sintonia entre seus dois mundos, onde então acontece o aprendizado(4).

Andraus $^{(5)}$ refere que a dramatização e o teatro de fantoches é mais eficaz do que exposição dialogada e demonstração. Chamamos a atenção para a observação sobre o quanto ensinar brincando é ainda a melhor estratégia.

Ao finalizarmos nossa apresentação entregamos desenhos para colorir salientando a importância da escovação na prevenção de problemas bucais, como uma maneira de avaliarmos o que foi fixado desta estratégia de ensino para crianças.

\section{RESULTADOS}

Neste relato do vivido pelos alunos do Curso de Graduação em Enfermagem pudemos evidenciar que os conteúdos teóricos desenvolvidos na Disciplina de Didática Aplicada ao Cuidado são fundamentais para a prática da Educação em Saúde, bem como a efetividade de uma ação interdisciplinar dentro do desenho pedagógico do referido curso. Dessa maneira, como profissionais da saúde, devemos estar abertos a novas possibilidades de desenvolver práticas/cuidados que atendam as necessidades do outro no seu próprio universo.

A referida disciplina permite-nos desenvolver múltiplas atividades no papel de educador e atividades de promoção à saúde. Assim, por meio desta prática educacional percebemos que a utilização de histórias, dramatização e manifestações artísticas atrai e motiva a criança a participar espontaneamente, oferecendo a possibilidade de criar, fantasiar e imaginar. O educando participa ativamente, o que faz com que ele se aproxime e reconheça suas dificuldades de assimilação do conteúdo e criem alternativas, assim as crianças torna-se consciente do conteúdo ministrado e deixa a posição passiva no processo de aprendizagem ${ }^{(7)}$.

\section{CONCLUSÃO}

Ao concluir este relato de experiência fica evidente a preocupação do docente da disciplina em motivar o alunado em desenvolver múltiplas estratégias de ensino, buscando que os discentes desenvolvam competências para seu desenvolvimento profissional e pessoal.

Nesta proposta fomos estimulados a abandonar nossa condição passiva, do aprendizado bancário e de apenas receber/ 
proporcionar conteúdos teóricos, para nos comprometer mais com o aprendizado das crianças. A possibilidade evidenciou a importância do professor em desenvolver a flexibilidade e abertura necessária para lidar com incertezas e medos, dando segurança para este caminho estando atentos aos movimentos necessários para as metodologias ativas.

Neste contexto, a aplicação do teatro como técnica de educação pode ser estimulada nas atividades de educação e saúde, já que é capaz de entreter, representar idéias e atitudes comportamentais da vida diária. Este traduz com clareza a mensagem que se deseja comunicar, levando a platéia a refletir sobre as ações do cotidiano. Reflexão essa que é essencial para o alcance de mudanças, inerente à evolução do desenvolvimento intelecto-socio-cultural do ser humano ${ }^{(6)}$.

Com essa experiência pudemos vislumbrar novas possibilidades de ensino e prática, o quanto é relevante a comunicação interdisciplinar bem como a importância do papel do enfermeiro educador na formação e aprendizado da criança.

\section{REFERÊNCIAS}

1. Dohme V. O lúdico na Educação. Rev Profissão Mestre. 2001;3(27):28-29.

2. Nitshke RG, Martins CR, Verdi M. O lúcido lúdico. Texto Contexto Enferm. 1998;7(3):118-129.

3. Nazima TJ, Codo CRB, Paes IADC, Bassinello GAH. Orientação em saúde por meio do teatro: relato de experiência. Rev. Gaúcha Enferm. 2008;29(1):147-151.

4. Ravelli APX, Motta MGC. O lúdico e o desenvolvimento infantil: um enfoque na música e no cuidado de enfermagem. Rev Bras Enferm. 2005;58(5):611-13.

5. Andraus LMS, Minamisava R, Borges IK, Barbosa MA. Primeiros Socorros para crianças: relato de experiência. Acta paul. enferm. 2005;18(2):220-225.

6. Araújo EG, Nunes MMLG. Atos e atores: o lúdico na educação em saúde. Rev Bras Enferm.1996;49(3):459-474.

7. Castro APR, Gonçalves AF, Caetano FHP, Souza LJEX. Brincando e aprendendo saúde. Texto Contexto Enferm. 1998;7(3):85-95. 